\title{
Uma Técnica para Obter Abundante Esporulação de Phytophthora palmivora
}

\author{
Gilson S. Silva ${ }^{1}$ \& Izumy P. Doihara ${ }^{1}$ \\ 'Universidade Estadual do Maranhão, CEP 65001-970, São Luís, MA, e-mail: gilson_soares@uol.com.br
}

(Aceito para publicação em 01/07/2003)

Autor para correspondência: Gilson Soares da Silva

\begin{abstract}
A technique to obtain abundant sporulation of Phytophthora palmivora

Abundant sporulation of Phytophthora palmivora was obtained by spraying papaya (Carica papaya)fruits with a mycelial

suspension of the fungi cultivated in potato-dextrose-agar. The fruits were kept in a moist chamber for $72 \mathrm{~h}$. Sporulation was higher than that obtained in the medium culture PDA, V-8 juice and carrot-agar.
\end{abstract}

A podridão das raízes e dos frutos do mamoeiro (Carica papaya L.), causada por Phytophthora palmivora (Butler) Butler, é uma das mais importantes doenças dessa cultura, especialmente nas regiões onde ocorrem altas precipitações pluviométricas e solos mal drenados. Esporângios e zoósporos são as principais estruturas responsáveis pela infecção e desenvolvimento da doença. A obtenção dessas estruturas, no entanto, nem sempre é alcançada nos meios de cultura convencionais. Neste trabalho, procurou-se obter abundante esporulação de $P$. palmivora de modo simples, rápido e com baixo custo. Frutos de mamão no estágio 2 de maturação (Costa \& Balbino. Mamão, Embrapa Inf. Tec. 2002) foram imersos em uma solução de hipoclorito de sódio a $2 \%$ durante $20 \mathrm{~min}$. Logo após lavados três vezes em água destilada e esterilizada, os frutos foram secos ao ar, postos em bandeja plástica forrada com papel toalha, pulverizados com uma suspensão de micélio de $P$. palmivora obtida de culturas do fungo desenvolvidas em BDA e deixados em câmara úmida por $72 \mathrm{~h}$, em condições ambientes de laboratório $\left(26 \pm 2^{\circ} \mathrm{C}\right)$. Para efeito de comparação, o mesmo isolado do fungo foi cultivado em meio de cenouraágar, V-8 ágar $+\mathrm{CaCO}_{3}$ e BDA em BOD a $25^{\circ} \mathrm{C}$, sob iluminação constante, durante dez dias. O delineamento experimental foi inteiramente casualizado, com quatro tratamentos (três meios de cultura e frutos de mamão) com seis repetições. Para efeito de análise estatística, o s dados foram transformados em $\sqrt{\mathrm{x}+0,5}$. Setenta e duas horas após a inoculação, os frutos, recobertos pelo crescimento do fungo, foram lavados com água destilada, a suspensão recolhida em béquer e, com o auxílio de um hemacitômetro, foi realizada a contagem do número de esporângios. A produção de esporângios nos meios de cultura foi avaliada vertendo-se $20 \mathrm{ml}$ de água/placa e raspando-se a superfície dos meios com pincel fino e a concentração determinada em hemacitômetro (Tabela 1). A produção de esporângios de $P$. palmivora sobre os frutos de mamão foi estatísticamente superior àquelas obtidas nos meios de cultura, BDA e cenoura-ágar. Não obstante o meio V-8 - ágar não tenha diferido estatisticamente da esporulação sobre frutos de mamão, quanto à produção de esporângios, observa-se que, em números reais, a esporulação do patógeno foi mais abundante em fruto do que no meio de cultura. Rocha (Rev. Theobroma 1:11-16. 1971) também obteve abundante esporulação de $P$. palmivora sobre frutos de cacau (Theobromae cacau L.), removendo a epiderme de frutos previamente inoculados e mantidos em câmara úmida por 72 $\mathrm{h}$, confirmando a importância de substratos naturais na esporulação desse patógeno. Além da rápida e fácil obtenção da esporulação de $P$. palmivora, sem a utilização de equipamentos e meios de cultura, esse novo método oferece, ainda, a vantagem de se ter um patógeno com a sua patogenicidade comprovada.

TABELA 1 - Esporulação de Phytophthora palmivora sobre frutos de mamão (Carica papaya) e em meios de cultura

\begin{tabular}{|c|c|}
\hline MEIO DE CLLILIRA & ESPORÂNGLO/ ml \\
\hline BDA & $2283.33 \mathrm{C}$ \\
\hline 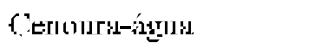 & $1328.3 .3 .3 \mathrm{r}$ \\
\hline V-s ágar & $19666,66 \mathrm{~A}$ \\
\hline Trutos de malmào & $24750,40 \mathrm{~A}$ \\
\hline \multicolumn{2}{|l|}{$\mathrm{CV}(\%)=10,80$} \\
\hline DYS 0.236 & \\
\hline
\end{tabular}

